\title{
Mutation breeding of high 4-androstene-3,17-dione-producing Mycobacterium neoaurum ZADF-4 by atmospheric and room temperature plasma treatment
}

\author{
Chao LIU ${ }^{1,2}$, Xian ZHANG ${ }^{1,2}$, Zhi-ming RAO ${ }^{\dagger 1,2}$, Ming-long SHAO ${ }^{1,2}$, \\ Le-le ZHANG ${ }^{1,2}$, Dan $\mathrm{WU}^{1,2}$, Zheng-hong $\mathrm{XU}^{3}$, Hui $\mathrm{LI}^{3}$ \\ ( ${ }^{1}$ Key Laboratory of Industrial Biotechnology, Ministry of Education, School of Biotechnology, Jiangnan University, Wuxi 214122, China) \\ ('2aboratory of Applied Microorganisms and Metabolic Engineering, School of Biotechnology, Jiangnan University, Wuxi 214122, China) \\ $\left({ }^{3}\right.$ Laboratory of Pharmaceutical Engineering, School of Pharmaceutical Science, Jiangnan University, Wuxi 214122, China) \\ †E-mail: raozhm@jiangnan.edu.cn \\ Received Oct. 15, 2014; Revision accepted Mar. 11, 2015; Crosschecked Mar. 18, 2015
}

\begin{abstract}
Steroid medication is used extensively in clinical applications and comprises a large and vital part of the pharmaceutical industry. However, the difficulty of separating 4-androstene-3,17-dione (AD) from 1,4-androstadiene3,17-dione (ADD) restricts the application of the microbial transformation of phytosterols in the industry. A novel atmospheric and room temperature plasma (ARTP) treatment, which employs helium as the working gas, was used to generate Mycobacterium neoaurum mutants producing large amounts of AD. After treatment of cultures with ARTP, four mutants were selected using a novel screening method with a color assay. Among the mutants, M. neoaurum ZADF-4 was considered the best candidate for industrial application. When the fermentation medium contained $15 \mathrm{~g} / \mathrm{L}$ phytosterols and was cultivated on a rotary shaker at $160 \mathrm{r} / \mathrm{min}$ at $30^{\circ} \mathrm{C}$ for $7 \mathrm{~d},(6.28 \pm 0.11) \mathrm{g} / \mathrm{L}$ of $A D$ and $(0.82 \pm 0.05) \mathrm{g} / \mathrm{L}$ of ADD were produced by the ZADF-4 mutant, compared with $(4.83 \pm 0.13) \mathrm{g} / \mathrm{L}$ of $A D$ and $(2.34 \pm 0.06) \mathrm{g} / \mathrm{L}$ of $A D D$ by the original strain, $M$. neoaurum ZAD. Compared with ZAD, the molar yield of AD increased from $48.3 \%$ to $60.3 \%$ in the ZADF-4 mutant. This result indicates that ZADF-4 may have potential for industrial production of AD.
\end{abstract}

Key words: Mycobacterium neoaurum, Atmospheric and room temperature plasma (ARTP), Mutation breeding, 4-Androstene-3,17-dione (AD), 1,4-Androstadiene-3,17-dione (ADD)

doi:10.1631/jzus.B1400274 Document code: A CLC number: Q933

\section{Introduction}

Steroid drugs occupy an important position in the pharmaceutical industry and have been widely used in clinical applications (Choi et al., 1995; Zhang W.Q. et al., 2013). Three general processes are used worldwide for steroid production: isolation from natural sources, synthesis from non-steroidal starting materials, and partial synthesis from steroid raw materials that have been isolated from plants and animals. Biotransformation provides an alternative route to chemical synthesis for the production of steroid medicine intermediates and has been used extensively as a routine and economical process in the pharmaceutical

\footnotetext{
Corresponding author

Project supported by the National Basic Research Program (973) of China (No. 2012CB725202), the National High-Tech R \& D Program (863) of China (No. 2011AA02A211), the National Natural Science Foundation of China (No. 21276110), the Fundamental Research Fund for the Central Universities (Nos. JUSRP51306A and JUSRP11545), the National 111 Project of China's Higher Education (No. 111-2-06), the Program of the Key Laboratory of Industrial Biotechnology, Ministry of Education, China (No. KLIB-KF201406), and the Priority Academic Program Development of Jiangsu Higher Education Institutions (PAPD), China

(D) ORCID: Chao LIU, http://orcid.org/0000-0002-5931-1722

(C) Zhejiang University and Springer-Verlag Berlin Heidelberg 2015
} 
industry (Wang et al., 2002; Huang et al., 2006; Zheng et al., 2011). Among the steroid drug intermediates, 4-androstene-3,17-dione (AD) and 1,4-androstadiene-3,17-dione (ADD) are the most important steroidal derivatives because they can be converted into a variety of steroidal drugs, such as sex hormones, adrenal cortical hormones, and other diverse steroids (van der Geize et al., 2000; 2001; Donova and Egorova, 2012). Recently, the microbial transformation of steroid intermediates from phytosterols has been reported. Several microorganisms including Mycobacterium, Rhodococcus, Nocardia, and Arthrobacter were found to have transformation capability (Bensasson et al., 1999; Wei et al., 2010a; Zhang W.Q. et al., 2013). Among them, Mycobacterium strains have been attracting increasing attention.

The microbial catabolic pathway of phytosterols has been well studied (Szentirmai, 1990; Donova and Egorova, 2012). The key reactions involved in structural steroid functionalization by Mycobacterium have been highlighted including sterol side-chain degradation, hydroxylation at various positions of the steroid core, and redox reactions (Donova and Egorova, 2012). Altogether, nine catabolic enzymes are involved in the steroid side-chain degradation pathway that functions in 14 consecutive enzymatic steps. These enzymes include $\omega$-oxygenase, alcohol dehydrogenase, aldehyde dehydrogenase, acyl-SCoA dehydrogenase, methy-crotonyl carboxylase, acylSCoA enoyl hydratase, acyl-SCoA thiophorase, $\beta$-keto thiolase, and $\beta$-hydroxyacyl-SCoA dehydrogenase. In total, three molecules of reduced flavin adenine dinucleotide $\left(\mathrm{FADH}_{2}\right)$, three of propionyl$\mathrm{SCoA}$, three of reduced form of nicotinamide-adenine dinucleotide (NADH), and one of acetic acid are formed, and the side-chain of one molecule of phytosterol is selectively removed (Szentirmai, 1990). The genome of Mycobacterium sp. VKM Ac-1817D has been reported to contain coding genes, including at least three genes of 3-ketosteroid- $\Delta^{1}$-dehydrogenase (KSDD, $k s d d)$, five genes of 3-ketosteroid-9 $\alpha$ hydroxylase (KSH) subunit $\mathrm{A}(k s h A)$, and one gene of KSH subunit B $(k s h B)$ (Bragin et al., 2013). In Mycobacterium, the microbial catabolic pathway of phytosterols is so complex that metabolic engineering with a rational design is very difficult. Recently, studies of Mycobacterium strains have reported that the solubility of phytosterols can be increased by adding hydroxypropyl- $\beta$-cyclodextrin (HP- $\beta$-CD) (Shen et al., 2012). This approach has been used for improving steroid biotransformation in aqueous media in strain ZJUVN-08 of M. neoaurum (Zhang X.Y. et al., 2013). In M. neoaurum strains, the productivity of transformation of sterols to sterones can be improved through enhancing the activity of cholesterol oxidases including cholesterol oxidase M1 (ChoM1) and ChoM2 (Yao et al., 2013). Our group has succeeded in cloning the KSDD coding gene, responsible for transforming $\mathrm{AD}$ to $\mathrm{ADD}$, from M. neoaurum JC-12 and over-expressing it to construct a Bacillus subtilis biocatalyst (Zhang W.Q. et al., 2013). The cholesterol oxidases ChoM1 and ChoM2 from $M$. neoaurum JC-12 were highly expressed in the recombinant strains 168/pMA5-choM1 and 168/pMA5choM2 of B. subtilis, respectively, and their activities were 5.2- and 7.3-fold higher, respectively, than those of the cholesterol oxidases in M. neoaurum JC-12 (Shao et al., 2014).

Microbial mutation breeding methods have been widely used in the fermentation industry, including the use of physical mutagens such as ultraviolet radiation and ion beams, and chemical mutagens such as sodium azide, diethyl sulphate, and ethyl methanesulphonate. Among these conventional mutation methods, issues of the health and safety of operators and mutation efficiency are always major concerns (Bhagwat and Duncan, 1998). Therefore, the development of an efficient breeding method for selecting highly productive AD mutants is highly desirable. In general, plasma is a partially or fully ionized gas and is sometimes known as the fourth and most energetic state of matter. Plasmas are usually classified as thermal or non-thermal. Usually, non-thermal plasmas are characterized by a palpable non-equilibrium between very hot electrons and cold heavy particles. Among the different types of atmospheric pressure non-equilibrium discharge (APNED) plasma sources, atmospheric and room temperature plasma (ARPT), which is driven by a radio frequency (RF) power supply with water-cooled, bare-metallic electrodes, has shown promise in applications in biotechnology (Zhang et al., 2014). In this context, the use of a novel mutation method such as ARTP has become increasingly popular due to its efficiency, safety, and environment-friendly nature (Hua et al., 2010; Wang et al., 2010; Li et al., 2014). 
To obtain the target mutants, a rational and effective screening method, as well as an efficient breeding method is needed. Zhang X. et al. (2013) used a novel and effective screening method to isolate successfully a mutant of high acetoin-producing B. subtilis blocked in 2,3-butanediol dehydrogenase. The property of 2,6-dichlorophenolindophenol (DCPIP) enabling it to be easily reduced by NADH was used to isolate the promising mutant. It has been reported that DCPIP can be reduced by $\mathrm{FADH}_{2}$ (Leitner et al., 2001; Brugger et al., 2014). On this basis, we planned to screen for mutants of $M$. neoaurum blocked in KSDD, which performs the $\Delta^{1}$-dehydrogenation of the steroid polycyclic ring structure in the conversion of AD to ADD, accompanied by the transform of $\mathrm{H}^{+}$ (Fig. 1) (Szentirmai, 1990). If the enzyme activity of KSDD is inactivated or reduced, the molar ratio of $\mathrm{AD} / \mathrm{ADD}$ in the production mixture will increase (Choi et al., 1995; Brzostek et al., 2005; Wei et al., 2010b).

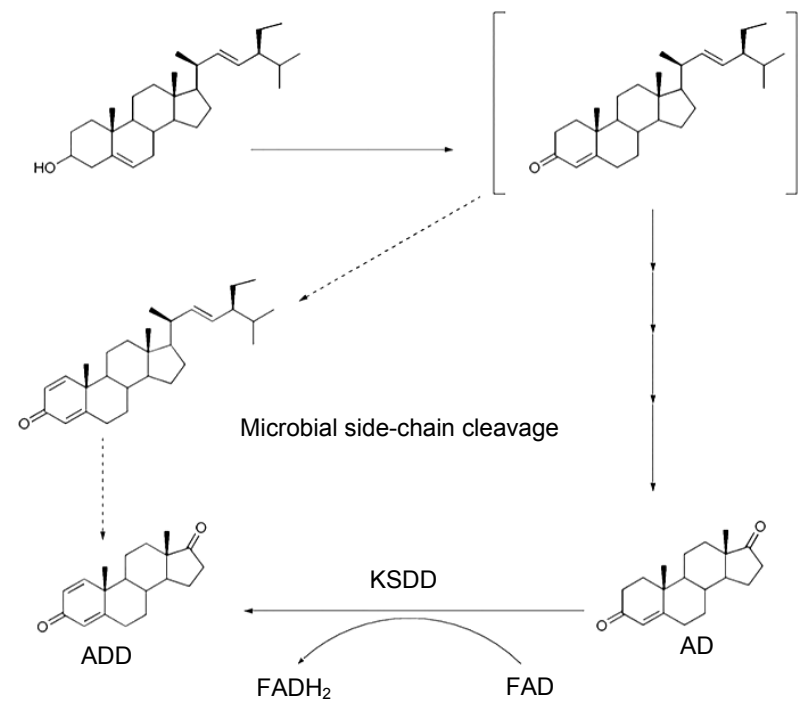

Fig. 1 Microbial transformation pathway from phytosterol to AD and ADD

Previously, our laboratory had isolated the ZAD strain of M. neoaurum (Fig. 2), which is capable of over-producing a mixture of $\mathrm{AD}$ and $\mathrm{ADD}$. In this study, by using novel mutagenesis ARPT and screening methods, a KSDD deficient $M$. neoaurum mutant was isolated and the AD yield in the product mix was significantly increased. This work provides a promising candidate of $M$. neoaurum for industrial AD production as well as an extension of the $\mathrm{H}^{+}$dependent dehydrogenase-deficient screening method.

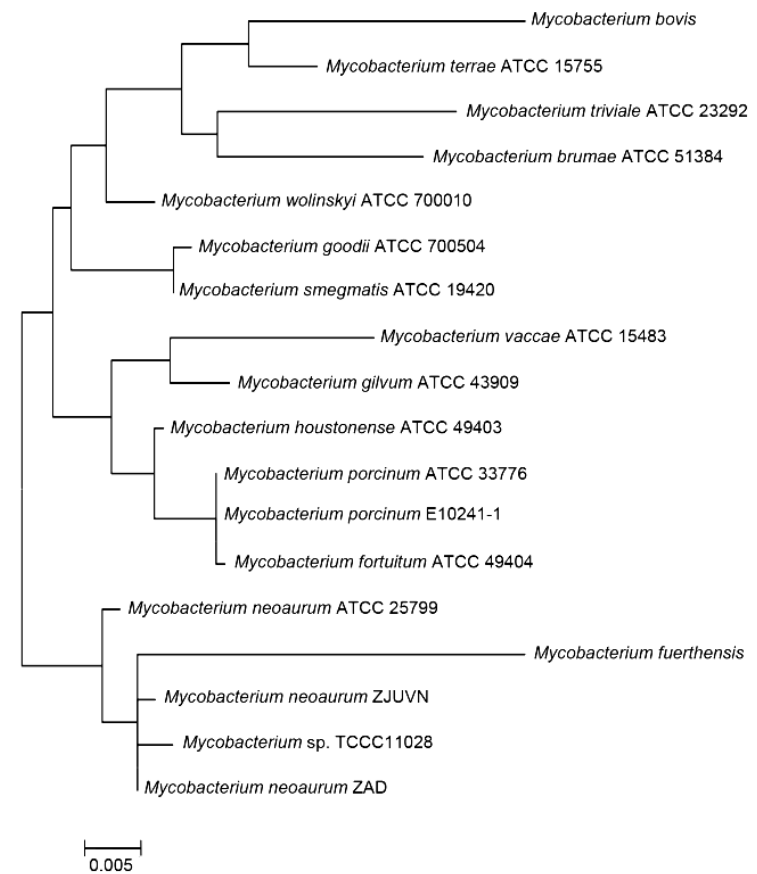

Fig. 2 Phylogenetic tree of ZAD in relation to other $M y$ cobacterium species

The phylogenetic tree was constructed based on comparison of $16 \mathrm{~S}$ rRNA sequences, demonstrating the position of ZAD among closely related species (accession number for the 16S rRNA sequence: Banklt1782326, Mycobacterium KP262026)

\section{Materials and methods}

\subsection{Bacterial strains, culture method, and chemicals}

Mycobacterium neoaurum ZAD was isolated from steroid-contaminated soil samples and stored in our lab. The seed medium contained $20 \mathrm{~g} / \mathrm{L}$ glucose, $10 \mathrm{~g} / \mathrm{L}$ tryptone, $6 \mathrm{~g} / \mathrm{L}$ beef extract, and $10 \mathrm{~g} / \mathrm{L} \mathrm{NaCl}$, adjusted to $\mathrm{pH}$ 8.0. The solid seed medium agar plates were prepared by adding $2 \%(0.02 \mathrm{~g} / \mathrm{ml})$ of agar. The fermentation medium contained: $20 \mathrm{~g} / \mathrm{L}$ glucose, $3 \mathrm{~g} / \mathrm{L} \mathrm{K}_{2} \mathrm{HPO}_{4}, 0.2 \mathrm{~g} / \mathrm{L} \mathrm{MgSO}_{4}, 5 \times 10^{-4} \mathrm{~g} / \mathrm{L} \mathrm{MnCl}_{2}$, $45 \mathrm{~g} / \mathrm{L}$ hydroxypropyl- $\beta$-cyclodextrin (Shandong Binzhou Zhiyuan Bio-Technology Co., Ltd., China), $15 \mathrm{~g} / \mathrm{L}$ phytosterol substrate, and $10 \mathrm{~g} / \mathrm{L}$ soy peptone, adjusted to $\mathrm{pH}$ 8.0. Strains were inoculated at $30^{\circ} \mathrm{C}$ on a rotary shaker at $160 \mathrm{r} / \mathrm{min}$. The AD and ADD standards were obtained from Sigma-Aldrich Chemical Co. (Germany). The phytosterol substrate used was a sterol mixture containing more than $95 \%$ stigmasterol (Zhejiang Huzhou Biolily Biotechnology Co., Ltd., China). Ex Taq polymerase and restriction enzymes were acquired from TaKaRa Co., Ltd. (Dalian, China). 


\subsection{Mutagenesis with the ARTP biological breeding system and mutant selection}

Mutation of ZAD using a pure helium plasma jet was carried out in the ARTP biological breeding system (supplied by Environment Biological Technology Laboratory, Department of Chemical Engineering, Tsinghua University, Beijing, China), which consisted of a coaxial type plasma generator, a gas supply control subsystem, a radio frequency $(13.56 \mathrm{MHz})$ power supply, and a sample plate made of stainless steel. In this study, the operating parameters were as follows: the radio frequency $(\mathrm{RF})$ power input was $40 \mathrm{~W}$, the gas flow was $12.5 \mathrm{~L} / \mathrm{min}$, the distance between the plasma torch nozzle exit and the sample plate (D) was $1 \mathrm{~cm}$, the temperature of the plasma jet was below $40^{\circ} \mathrm{C}$, and the plasma treatment time ranged from 60 to $180 \mathrm{~s}$ (Wang et al., 2010; Li et al., 2014; Zhang et al., 2014).

The original strain was cultivated in the seed medium at $30^{\circ} \mathrm{C}$ and $160 \mathrm{r} / \mathrm{min}$ for $42-44 \mathrm{~h}$. The cell concentration was adjusted to $1.0 \times 10^{6}-1.0 \times 10^{7} \mathrm{ml}^{-1}$ with sterile distilled water. A $10-\mu 1$ aliquot of the above culture solution was applied to a sterilized sample plate and dried in sterile nitrogen for a few minutes (Wang et al., 2010). The bacterial samples were then exposed to the plasma jet downstream of the plasma torch nozzle exit for a given time. After the sample had been treated for a predetermined time, the plates were put into new tubes and washed with sterile distilled water to form the treated culture solution. The culture solution was then spread on the solid seed medium and cultivated at $30^{\circ} \mathrm{C}$ for $2 \mathrm{~d}$.

For selection of mutants, a filter assay was used for the detection of KSDD activity. During the working process of $\mathrm{KSDD}$, a molecule of $\mathrm{FADH}_{2}$ is generated. The reducibility of $\mathrm{FADH}_{2}$ can degrade DCPIP effectively, while a mutant would lose the ability to generate $\mathrm{FADH}_{2}$ after the KSDD was inactivated or reduced (Szentirmai, 1990). KSDD, as a flavin-dependent oxidoreductase, has a reaction mechanism consisting typically of two half-reactions. In the reductive half-reaction, an electron donor substrate is reduced (Reaction 1). In the ensuing oxidative half-reaction, the reduced flavin is re-oxidized by the second substrate oxygen, yielding the oxidized prosthetic group and $\mathrm{H}_{2} \mathrm{O}_{2}$ (shown as reduced $\mathrm{FADH}_{2}$ in Reaction 2), or by alternative electron acceptors such as quinones, redox dyes, or chelated metal ions.
The two-electron redox systems of the redox dye DCPIP are shown in Reaction 3 (Brugger et al., 2014), which is the theoretical basis for selecting the target strains. The related reactions are: (1) enzyme-FAD+ substrate $\rightarrow$ enzyme-FADH ${ }_{2}+$ product; (2) $\mathrm{FADH}_{2}+$ $\mathrm{O}_{2} \rightarrow \mathrm{FAD}+\mathrm{H}_{2} \mathrm{O}_{2} ; \quad$ (3) $\mathrm{DCPIP}+2 \mathrm{e}^{-}+2 \mathrm{H}^{+} \rightarrow \mathrm{DCPIH}_{2}$. Single colonies on seed agar plates were picked onto gridded sterile membrane filters $(47 \mathrm{~mm}$ diameter, $0.45 \mu \mathrm{m}$ pore size; Sartorius Stedim Biotech Co., Ltd., Germany), which were placed on the surface of seed plates and cultivated at $30{ }^{\circ} \mathrm{C}$ for about $2 \mathrm{~d}$. Then the filters were carefully taken out, floated colony side up on $2 \mathrm{ml}$ of a solution of $4 \mathrm{mg} / \mathrm{ml}$ DCPIP (Sigma) in $0.1 \mathrm{~mol} / \mathrm{L}$ potassium phosphate buffer $(\mathrm{pH} 7.0)$ and incubated at $30{ }^{\circ} \mathrm{C}$ for about $1 \mathrm{~d}$ until all the colonies were dyed deep blue. Excess DCPIP was wiped off the filters with a dry sterile filter paper, and then the filters were floated on $3 \mathrm{ml}$ of a $250 \mathrm{mmol} / \mathrm{L}$ solution of $\mathrm{AD}(2 \%$ methanol and $50 \mathrm{mmol} / \mathrm{L}$ Tris buffer, $\mathrm{pH}$ 7.0). KSDD-positive strains became yellow in about 15 min following the above treatment, while KSDD-deficient strains remained blue. The blue strains were then streak purified on seed agar plates (Nicholson, 2008; Zhang X. et al., 2013).

\subsection{Cloning of the ksdd gene}

The ksdd gene was cloned from the chromosomal DNA of mutants using the forward primer 5'-accggaattcgtgttctacatgactgcccagg-3' and reverse primer 5'-gacggatcctcaggcctttccagcgagatg-3'. Polymerase chain reaction (PCR) amplification was performed using Ex Taq, a thermo stable polymerase, in Ex Taq buffer. The scheme of amplification included 35 cycles with the following conditions: initial denaturation at $95{ }^{\circ} \mathrm{C}$ for $4 \mathrm{~min}$, followed by 35 cycles of denaturation $\left(45 \mathrm{~s}\right.$ at $\left.95{ }^{\circ} \mathrm{C}\right)$, annealing $(50 \mathrm{~s}$ at $\left.63{ }^{\circ} \mathrm{C}\right)$, and extension $\left(120 \mathrm{~s}\right.$ at $\left.72{ }^{\circ} \mathrm{C}\right)$, and a final elongation step $\left(10 \mathrm{~min}\right.$ at $\left.72{ }^{\circ} \mathrm{C}\right)$. The desired band was excised and gel purified. The PCR reaction was performed using an automated thermocycler (Whatman Biometra, Gottingen, Germany).

\subsection{Fermentation experiments and product assay}

For AD fermentation, the cells from each seed medium plate were inoculated into $10 \mathrm{ml}$ of seed medium broth and cultivated on a rotary shaker at $160 \mathrm{r} / \mathrm{min}$ at $30{ }^{\circ} \mathrm{C}$ for about $24 \mathrm{~h}$. Then $1 \mathrm{ml}$ of culture was transferred into $50 \mathrm{ml}$ of seed medium at 
$160 \mathrm{r} / \mathrm{min}$ at $30^{\circ} \mathrm{C}$. After $24 \mathrm{~h}$ of culture growth, the seed culture was inoculated into $100 \mathrm{ml}$ of fermentation medium and cultured for about $7 \mathrm{~d}$. The inoculation volume was $10 \%$ of seed culture. Cell free supernatants were harvested every $24 \mathrm{~h}$ through centrifugation for $10 \mathrm{~min}$ at $10000 \mathrm{r} / \mathrm{min}$ and then stored at $-20{ }^{\circ} \mathrm{C}$ for further use.

The steroids extracted from the bioconversion $(1 \mathrm{ml})$ by ethyl acetate were used for high performance liquid chromatography (HPLC) and thin-layer chromatography (TLC) analyses. For HPLC analysis, the products were diluted five times with ethyl acetate and filtered (nylon syringe filter, pore size $0.22 \mu \mathrm{m}$ ), then analyzed by HPLC with the following conditions: column, reversed phase Diamonsil C18 (Dikma Technologies, USA); column temperature, $30{ }^{\circ} \mathrm{C}$; mobile phase, methanol-water $(70: 30, \mathrm{v} / \mathrm{v})$; flow rate of mobile phase, $1 \mathrm{ml} / \mathrm{min}$. Analytes were detected with UV simultaneously at $254 \mathrm{~nm}$. For TLC analysis, sample extracts were spotted in 5- $\mu$ l aliquots onto TLC plates. Silica gel TLC plates with petroleum ether/ethyl acetate $(6: 4, \mathrm{v} / \mathrm{v})$ as the solvent system were used. The TLC plates were dyed by $20 \%$ sulfuric acid at $100{ }^{\circ} \mathrm{C}$ for $10 \mathrm{~min}$ (Wei et al., 2010a; 2010b; Zhang W.Q. et al., 2013).

\subsection{Preparation of cell-free extracts and KSDD enzyme activity assay}

Cells were grown in fermentation medium for $7 \mathrm{~d}$ on a $500-\mathrm{ml}$ rotary shaker at $30^{\circ} \mathrm{C}$ and $160 \mathrm{r} / \mathrm{min}$. Cell pellets $\left(8000 \mathrm{r} / \mathrm{min}, 10 \mathrm{~min}, 4^{\circ} \mathrm{C}\right)$ were washed three times with $50 \mathrm{ml} 50 \mathrm{mmol} / \mathrm{L}$ Tris- $\mathrm{HCl}$ buffer (pH 7.0). Cell pellets were suspended in Tris- $\mathrm{HCl}$ buffer $(50 \mathrm{mmol} / \mathrm{L}$ Tris- $\mathrm{HCl} \mathrm{pH} 7.0,2 \mu \mathrm{g} / \mathrm{ml}$ phenylmethanesulfonyl fluoride (PMSF)) with a 1:2 (v/v) ratio, then the suspension was intermittently sonicated in an ice bath to disrupt the cells using 300 pulses of $7 \mathrm{~s}$ each (sonicated for $2 \mathrm{~s}$ and paused for $5 \mathrm{~s}$ ) at $30 \%$ energy setting $(300 \mathrm{~W})$. Cell extracts were centrifuged for $30 \mathrm{~min}$ at $10000 \mathrm{r} / \mathrm{min}$ in a Sigma $3 \mathrm{~K}-15$ centrifuge (Sigma, Germany) to remove the cell debris. The resulting supernatant of the culture was used for KSDD enzyme assays or stored at $-20^{\circ} \mathrm{C}$.

KSDD activity was visualized by incubating native polyacrylate gel electrophoresis (PAGE) in $100 \mathrm{ml} 50 \mathrm{mmol} / \mathrm{L}$ Tris- $\mathrm{HCl}$ buffer containing $3.1 \mathrm{mg}$ phenazine methosulphate, $2.9 \mathrm{mg}$ steroid (AD in $500 \mu \mathrm{l}$ ethanol), and $41 \mathrm{mg}$ nitroblueterazolium (NBT) dissolved in $500 \mu 170 \%$ dimethylformamide. Staining was done for several hours until clear activity bands were visible. The reaction was stopped with $10 \%$ acetic acid. No KSDD activity stain was found in controls with ADD. Enzyme activities were measured spectrophotometrically at $30{ }^{\circ} \mathrm{C}$ using phenazine methosulfate (PMS) and DCPIP. The reaction mixture $(1 \mathrm{ml})$ consisted of $50 \mathrm{mmol} / \mathrm{L}$ Tris- $\mathrm{HCl}$ buffer (pH 7.0), $1.5 \mathrm{mmol} / \mathrm{L}$ PMS, $40 \mu \mathrm{mol} / \mathrm{L}$ DCPIP, an appropriate concentration of the supernatant or cell extract, and $250 \mathrm{mmol} / \mathrm{L} \mathrm{AD}$ in $2 \%$ methanol. Activity is expressed as $\mathrm{U} / \mathrm{mg}$ of protein; $1 \mathrm{U}$ is defined as the reduction of $1 \mu \mathrm{mol} / \mathrm{min}$ DCPIP $\left(\xi_{600 \mathrm{~nm}}=18.7 \times\right.$ $\left.10^{3} \mathrm{~L} /(\mathrm{mol} \cdot \mathrm{cm})\right)$. No activity was detected in reaction mixture lacking AD (Wei et al., 2010b; Zhang W.Q. et al., 2013).

\section{Results}

\subsection{Mutagenesis and mutant selection}

It has been reported that ARTP has a higher positive genotoxic response than traditional mutation methods, making it a potentially effective mutation breeding strategy (Hua et al., 2010; Wang et al., 2010; Li et al., 2014; Zhang et al., 2014). In this study, ARTP-irradiation was used for inducing random mutations, and high AD-producing $M$. neoaurum mutants were selected later. $M$. neoaurum cells were treated with the helium-based ARTP for 60, 90, 120, 150 , or $180 \mathrm{~s}$, and the optimal exposure time was determined to be $150 \mathrm{~s}$ with lethality from $90 \%$ to 96\% (data not shown). Therefore, the exposure time employed in subsequent studies was set at $150 \mathrm{~s}$. After ARTP mutation, high KSDD-activity strains were converted to yellow by the filter assay using the treatments described above, while four KSDDdeficient mutants that retained a blue color were isolated. These mutants were then streak purified for further characterization. Fig. 3 shows the screening process used to isolate ZADF-4 (one of the reduced KSDD mutant strains). After the first screening process, a single colony (Fig. 3a) of ZADF-4 was separated and checked by repeating the filter assay to obtain a pure mutant (Fig. 3b). Floating the filter on the AD solution clearly showed that ZADF-4 remained blue, while KSDD-positive strains quickly turned yellow. 
(a)

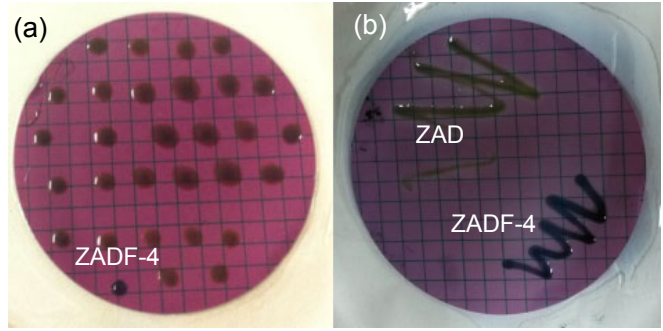

Fig. 3 Filter assay of mutant strain ZADF-4 Colonies were pre-stained with DCPIP and photographed about 15 min after incubation with AD dissolved in $2 \%$ methanol

\subsection{Enzyme activity assay of KSDD}

KSDD plays a key role in the process of transforming $\mathrm{AD}$ to $\mathrm{ADD}$, and therefore $\mathrm{KSDD}$ activity is vital for metabolic flux distribution involved in $\mathrm{AD}$ and ADD productions. The activity of KSDD in the original strain was $(3.24 \pm 0.05) \mathrm{U} / \mathrm{mg}$, while of the four mutants with reduced KSDD activity, ZADF-4 showed the lowest activity ((0.61 \pm 0.02$) \mathrm{U} / \mathrm{mg}$; Fig. 4$)$, a reduction of about $81.2 \%$. It was obvious that the activity of KSDD was reduced and the proportion of $\mathrm{AD}$ increased significantly (Fig. 4). A crude cell extract was prepared and assayed by native PAGE as described above. Staining for KSDD activity on native PAGE gels loaded with extracts of ZAD clearly revealed a stronger activity band than the KSDD deficient mutant, ZADF-4 (Fig. 5).

\subsection{Product analyses of $M$. neoaurum ZAD and ZADF-4}

It has been reported that fast growing mycobacteria can degrade natural sterols and use them as a source of carbon and energy (Nagasawa et al., 1969; Biggs et al., 1977). Preliminary fermentation of these mutants was studied using the methods described above, and the products were detected after $3 \mathrm{~d}$. The fermentation results for ZAD and ZADF-4 showed that the highest $\mathrm{AD}$ production was observed on Day 7 (Fig. 6). TLC analysis revealed that when cultured in fermentation medium the original strain could transform phytosterols efficiently and accumulate $\mathrm{AD}$ and ADD simultaneously, while the mutant ZADF-4 reduced the proportion of ADD in the product mixture significantly (Fig. 7a). The HPLC result for ZADF-4 showed that this strain accumulated $\mathrm{AD}$ as the main product, with $\mathrm{AD} / \mathrm{ADD}$ molar yields of about $8: 1$

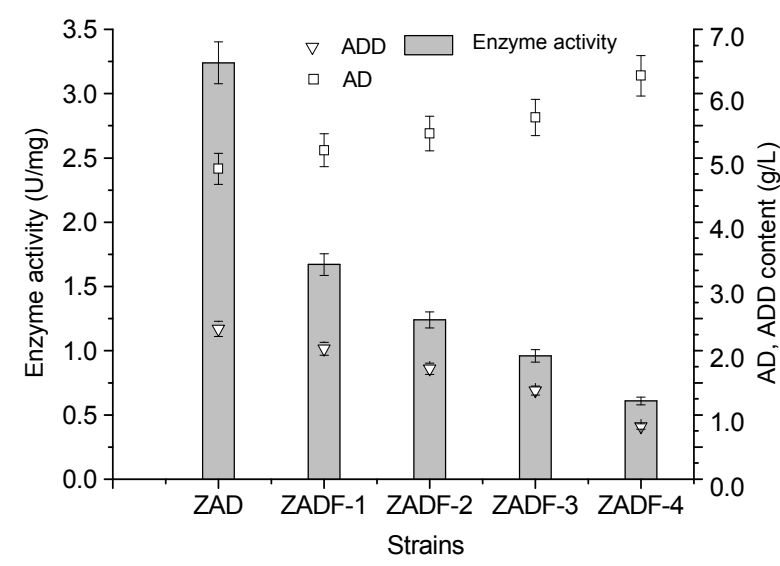

Fig. 4 KSDD activity and AD and ADD contents of ZAD and the mutants

Strains were cultured in fermentation medium and cultivated as described above. Enzyme activity was detected after $4 \mathrm{~d}$. Data were expressed as mean \pm standard diviation (SD). All assays were performed with triplicate cultures

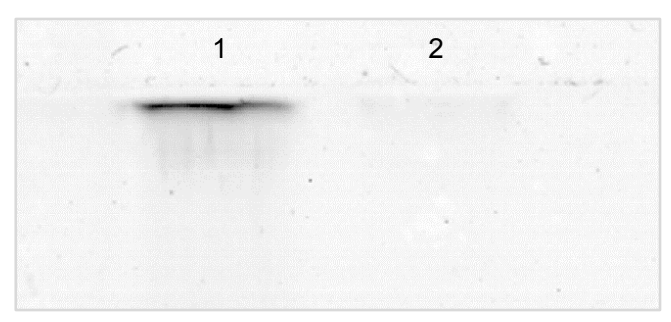

Fig. 5 KSDD activity staining on native PAGE gels using AD as substrate, loaded with appropriate concentrations of cell extracts

Lane 1, M. neoaurum ZAD; Lane 2 M. neoaurum ZADF-4

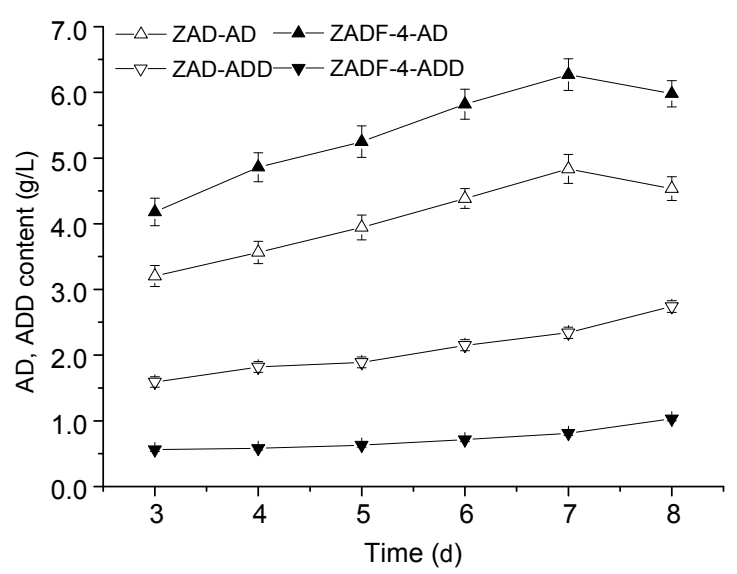

Fig. 6 Time course of AD and ADD accumulation by M. neoaurum ZAD and M. neoaurum ZADF-4

Data were expressed as mean $\pm \mathrm{SD}(n=3)$ 
(Fig. 7b). In the transformation experiments with shake flasks, ZADF-4 exhibited an increased product ratio of $\mathrm{AD}$ :ADD compared with the original strain (Table 1). Among the four mutants, ZADF-4 achieved the highest ratio of $\mathrm{AD}$ in the product mixtures (Fig. 4 and Table 1; the specific data of the other mutants are not shown). The ability to transform phytosterols to AD was improved noticeably in ZADF-4, and it was then selected as a promising AD producer for further studies.

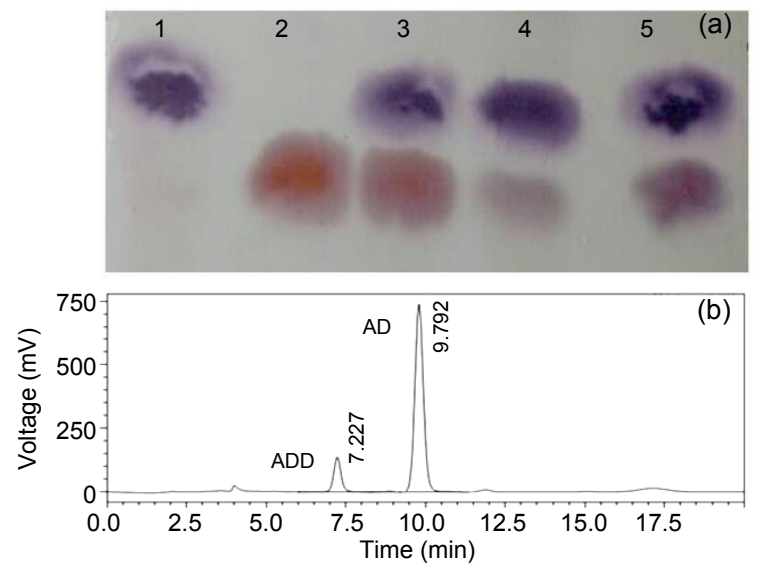

Fig. 7 TLC and HPLC analyses of fermentation products (a) TLC analysis of transformation products. Lane 1: standard sample of $\mathrm{AD}$; Lane 2: standard sample of ADD; Lane 3: standard mixture of AD and ADD; Lane 4: products from $7 \mathrm{~d}$ cultures of $M$. neoaurum ZADF-4; Lane 5: products from $7 \mathrm{~d}$ cultures of ZAD. (b) HPLC analysis of $M$. neoaurum ZADF-4 from $7 \mathrm{~d}$ cultures

Table 1 Comparison of products between ZAD and ZADF-4

\begin{tabular}{lcccc}
\hline Strain & $\begin{array}{c}\mathrm{AD} \\
(\mathrm{g} / \mathrm{L})^{*}\end{array}$ & $\begin{array}{c}\text { ADD } \\
(\mathrm{g} / \mathrm{L})^{*}\end{array}$ & $\begin{array}{c}\text { Molar } \\
\text { ratio of } \\
\text { AD:ADD }\end{array}$ & $\begin{array}{c}\text { Molar } \\
\text { yield of } \\
\mathrm{AD}(\%)\end{array}$ \\
\hline ZAD & $4.83 \pm 0.13$ & $2.34 \pm 0.06$ & $2: 1$ & 48.3 \\
ZADF-4 & $6.28 \pm 0.11$ & $0.82 \pm 0.05$ & $8: 1$ & 60.3 \\
\hline
\end{tabular}

${ }^{*}$ Data were expressed as mean $\pm \mathrm{SD}(n=3)$

\subsection{Sequencing of the mutant $k s d d$ gene}

After screening, ZADF-4 was chosen as the most promising candidate high $\mathrm{AD}$-producing strain. The $k s d d$ gene of ZADF-4 was amplified and sequenced, and compared with that of ZAD (GenBank accession number for ksdd in M. neoaurum ZAD: Banklt1783760, Mycobacterium KP284440). In the 5'-terminal sequence of $k s d d$, the mutant ZADF-4 is missing nine nucleotides (atgttctac) compared with ZAD. Therefore, the translation of KSDD in ZADF-4 is reduced by three amino acids (MFY). Moreover, there are two point mutations in the $k s d d$ gene of ZADF-4, one of which is a silent mutation $(\mathrm{g} .15 \mathrm{a}>6 \mathrm{t})$, while the other signal base change (g.413c $>404 t)$ resulted in a missense mutation ( $p .138 \mathrm{~S}>135 \mathrm{~L})$ in the translation of KSDD. The mutations caused amino acid changes, which ultimately caused the reduction of KSDD activity in ZADF-4.

\section{Discussion}

In recent years, with the increasing consumption of steroid drugs, the use of biotransformation in the production of steroid medicine intermediates has attracted more attention because it is highly efficient, safe, and environmentally friendly (Fernandes et al., 2003; Swizdor et al., 2012). The strain of ZAD stored in our lab could efficiently transform phytosterols to $\mathrm{AD}$ and $\mathrm{ADD}$, the most important steroid intermediates. However, due to their structural similarity, the presence of $\mathrm{AD}$ and $\mathrm{ADD}$ in the product mix significantly complicates their purification and decreases their final yields, thus impeding further commercial application of many promising strains (van der Geize et al., 2001; Wei et al., 2014). The possibility of using ZAD in industry would be enhanced if the proportion of AD or ADD could be enhanced significantly. In $M$. neoaurum NwIB-04, the enzyme KSDD has been augmented through genetic manipulation to obtain mutants with good ADD production and to overcome the difficulty of separating AD from ADD (ADD $4.94 \mathrm{~g} / \mathrm{L}, \mathrm{AD} 0.096 \mathrm{~g} / \mathrm{L}$ ), a key constraint to the microbial transformation of phytosterols in industry (Wei et al., 2010b). For the M. neoaurum strain ZJUVN-08, under optimal process conditions, the molar ratio of HP- $\beta-C D$ to phytosterol is $1.92: 1$, $8.98 \mathrm{~g} / \mathrm{L}$ phytosterol, at $120 \mathrm{~h}$ of incubation time, and the maximum $\mathrm{AD}$ yield is $5.96 \mathrm{~g} / \mathrm{L}$ (Zhang X.Y. et al., 2013). Living cells of Mycobacterium sp. NRRL B-3683 were immobilized by adsorption on activated alumina to produce ADD from cholesterol. When glucose and peptone were added to the reaction medium, the maximum productivity of ADD was about $0.19 \mathrm{~g} / \mathrm{L}$ per day with a molar conversion rate of $77 \%$ when $1.0 \mathrm{~g} / \mathrm{L}$ of cholesterol was added (Lee and Liu, 
1992). The strain of Mycobacterium sp. VKM Ac1815D was found to convert ergosterol and its 3 -acetate mainly to $\mathrm{AD}$. The molar yield of $\mathrm{AD}$ from $12.06 \mathrm{mmol} / \mathrm{L}(4.78 \mathrm{~g} / \mathrm{L})$ ergosterol reached $58.6 \%$ after $120 \mathrm{~h}$. ADD and 20-hydroxymethylpregn-4ene-3-one (HMP) were formed as minor products (Dovbnya et al., 2010). Relevant studies using Rhodococcus erythropolis have been reported. However, this study focuses on breeding high AD-producing $M$. neoaurum strains by isolating KSDD-deficient mutants.

Fortunately, in this study, a mutant of $M$. neoaurum, ZADF-4, with high AD production was obtained using the ARTP mutation technique and a novel and effective screening method. By using the ARTP mutation technique to modify the gene $k s d d$ encoding KSDD, a critical enzyme involved in steroid metabolism, the composition of the fermentation products was changed. In fermentation experiments, the strain ZADF-4 converted $15 \mathrm{~g} / \mathrm{L}$ of soybean phytosterols to $(6.28 \pm 0.11) \mathrm{g} / \mathrm{L} \mathrm{AD}$ (molar yield of $60.3 \%)$ and $(0.82 \pm 0.05) \mathrm{g} / \mathrm{L}$ ADD on Day 7 , compared with only $(4.83 \pm 0.13) \mathrm{g} / \mathrm{L} \mathrm{AD}$ (molar yield of $48.3 \%)$ and $(2.34 \pm 0.06) \mathrm{g} / \mathrm{L}$ ADD by the original strain (Table 1). Compared with the original strain, the mutant ZADF-4 not only improved the proportion of $\mathrm{AD}$ in the total product mix, but also increased the production of AD. Therefore, it could be a promising candidate for accumulating $\mathrm{AD}$ for industrial applications.

\section{Conclusions}

In the present work, we obtained a high $\mathrm{AD}$ producing mutant of $M$. neoaurum, ZADF-4, using the ARTP mutation technique and an $\mathrm{H}^{+}$-dependent dehydrogenase-deficient screening method. The mutant was identified as the best candidate for industrial application. Compared with the original strain, the accumulation and proportion of $\mathrm{AD}$ were significantly enhanced. Therefore, the study successfully provided a mutant, ZADF-4, which could be used as a promising candidate for accumulating $\mathrm{AD}$ for industrial applications.

\section{Compliance with ethics guidelines}

Chao LIU, Xian ZHANG, Zhi-ming RAO, Ming-long SHAO, Le-le ZHANG, Dan WU, Zheng-hong XU, and Hui LI declare that they have no conflict of interest.
This article does not contain any studies with human or animal subjects performed by any of the authors.

\section{References}

Bensasson, C.S., Hanson, J.R., Le Huerou, Y., 1999. The microbiological hydroxylation of $3 \alpha, 5$-cycloandrostanes by Cephalosporium aphidicola. Phytochemistry, 52(7): 1279-1282. [doi:10.1016/S0031-9422(99)00415-X]

Bhagwat, B., Duncan, E.J., 1998. Mutation breeding of banana cv. Highgate (Musa spp., AAA Group) for tolerance to Fusarium oxysporum f. sp. cubense using chemical mutagens. Sci. Hortic. (Amsterdam), 73(1):11-22. [doi:10. 1016/S0304-4238(97)00141-6]

Biggs, C.B., Pyke, T.R., Wovcha, M.G., et al., 1977. Microbial Transformation of Steroids. US Patent 4062729.

Bragin, E.Y., Shtratnikova, V.Y., Dovbnya, D.V., et al., 2013. Comparative analysis of genes encoding key steroid core oxidation enzymes in fast-growing Mycobacterium spp. strains. J. Steroid Biochem. Mol. Biol., 138:41-53. [doi:10. 1016/j.jsbmb.2013.02.016]

Brugger, D., Krondorfer, I., Zahma, K., et al., 2014. Convenient microtiter plate-based, oxygen-independent activity assays for flavin-dependent oxidoreductases based on different redox dyes. Biotechnol. J., 9(4):474482. [doi:10.1002/biot.201300336]

Brzostek, A., Sliwinski, T., Rumijowska-Galewicz, A., et al., 2005. Identification and targeted disruption of the gene encoding the main 3-ketosteroid dehydrogenase in Mycobacterium smegmatis. Microbiology, 151(7):23932402. [doi:10.1099/mic.0.27953-0]

Choi, K.P., Murooka, Y., Molnár, I., 1995. Secretory overproduction of Arthrobacter simplex 3-ketosteroid $\Delta^{1}$-dehydrogenase by Streptomyces lividans with a multicopy shuttle vector. Appl. Microbiol. Biotechnol., 43(6): 1044-1049. [doi:10.1007/BF00166923]

Donova, M.V., Egorova, O.V., 2012. Microbial steroid transformations: current state and prospects. Appl. Microbiol. Biotechnol., 94(6):1423-1447. [doi:10.1007/ s00253-012-4078-0]

Dovbnya, D.V., Egorova, O.V., Donova, M.V., 2010. Microbial side-chain degradation of ergosterol and its 3 -substituted derivatives: a new route for obtaining of deltanoids. Steroids, 75(10):653-658. [doi:10.1016/j. steroids.2010.04.001]

Fernandes, P., Cruz, A., Angelova, B., et al., 2003. Microbial conversion of steroid compounds: recent developments. Enzyme Microb. Technol., 32(6):688-705. [doi:10.1016/ S0141-0229(03)00029-2]

Hua, X.F., Wang, J., Wu, Z.J., et al., 2010. A salt tolerant Enterobacter cloacae mutant for bioaugmentation of petroleum- and salt-contaminated soil. Biochem. Eng. J., 49(2):201-206. [doi:10.1016/j.bej.2009.12.014]

Huang, C.L., Chen, Y.R., Liu, W.H., 2006. Production of androstenones from phytosterol by mutants of Mycobacterium sp. Enzyme Microb. Technol., 39(2):296-300. [doi:10.1016/j.enzmictec.2005.10.017] 
Lee, C.Y., Liu, W.H., 1992. Production of androsta-1,4diene-3,17-dione from cholesterol using immobilized growing cells of Mycobacterium sp. NRRL B-3683 adsorbed on solid carriers. Appl. Microbiol. Biotechnol., 36(5):598-603. [doi:10.1007/BF00183235]

Leitner, C., Volc, J., Haltrich, D., 2001. Purification and characterization of pyranose oxidase from the white rot fungus Trametes multicolor. Appl. Environ. Microbiol., 67(8):3636-3644. [doi:10.1128/AEM.67.8.3636-3644.2001]

Li, H.G., Luo, W., Wang, Q., et al., 2014. Direct fermentation of gelatinized cassava starch to acetone, butanol, and ethanol using Clostridium acetobutylicum mutant obtained by atmospheric and room temperature plasma. Appl. Biochem. Biotechnol., 172(7):3330-3341. [doi:10. 1007/s12010-014-0765-x]

Nagasawa, M., Bae, M., Tamura, G., et al., 1969. Microbial transformation of sterols. Agric. Biol. Chem., 33(11): 1644-1650. [doi:10.1271/bbb1961.33.1644]

Nicholson, W.L., 2008. The Bacillus subtilis ydjL (bdhA) gene encodes acetoin reductase/2,3-butanediol dehydrogenase. Appl. Environ. Microbiol., 74(22):6832-6838. [doi:10. 1128/AEM.00881-08]

Shao, M.L., Rao, Z.M., Zhang, X., et al., 2014. Bioconversion of cholesterol to 4-cholesten-3-one by recombinant $\mathrm{Ba}$ cillus subtilis expressing choM gene encoding cholesterol oxidase from Mycobacterium neoaurum JC-12. J. Chem. Technol. Biotechnol., in press. [doi:10.1002/jctb.4491]

Shen, Y.B., Wang, M., Li, H.N., et al., 2012. Influence of hydroxypropyl- $\beta$-cyclodextrin on phytosterol biotransformation by different strains of Mycobacterium neoaurum. J. Ind. Microbiol. Biotechnol., 39(9):1253-1259. [doi:10.1007/s10295-012-1130-0]

Swizdor, A., Kolek, T., Panek, A., et al., 2012. Selective modifications of steroids performed by oxidative enzymes. Curr. Org. Chem., 16(21):2551-2582. [doi:10. 2174/138527212804004625]

Szentirmai, A., 1990. Microbial physiology of sidechain degradation of sterols. J. Ind. Microbiol., 6(2):101-115. [doi:10.1007/BF01576429]

van der Geize, R., Hessels, G.I., van Gerwen, R., et al., 2000. Targeted disruption of the $k s t D$ gene encoding a 3-ketosteroid $\Delta^{1}$-dehydrogenase isoenzyme of Rhodococcus erythropolis strain SQ1. Appl. Environ. Microbiol., 66(5):2029-2036. [doi:10.1128/AEM.66.5.2029-2036.2000]

van der Geize, R., Hessels, G.I., van Gerwen, R., et al., 2001. Unmarked gene deletion mutagenesis of $k s t D$, encoding 3-ketosteroid $\Delta^{1}$-dehydrogenase, in Rhodococcus erythropolis SQ1 using $s a c B$ as counter-selectable marker. FEMS Microbiol. Lett., 205(2):197-202. [doi:10.1111/j. 1574-6968.2001.tb10947.x]

Wang, L.Y., Huang, Z.L., Li, G., et al., 2010. Novel mutation breeding method for streptomyces avermitilis using an atmospheric pressure glow discharge plasma. J. Appl. Microbiol., 108(3):851-858. [doi:10.1111/j.1365-2672. 2009.04483.x]
Wang, Z.F., Huang, Y.L., Rathman, J.F., et al., 2002. Lecithin-enhanced biotransformation of cholesterol to androsta-1,4-diene-3,17-dione and androsta-4-ene-3,17dione. J. Chem. Technol. Biotechnol., 77(12):1349-1357. [doi:10.1002/jctb.728]

Wei, W., Fan, S.Y., Wang, F.Q., et al., 2010a. A new steroid transforming strain of Mycobacterium neoaurum and cloning of 3-ketosteroid 9- $\alpha$-hydroxylase in NwIB-01, Appl. Biochem. Biotechnol., 162(5):1446-1456. [doi:10. 1007/s12010-010-8919-y]

Wei, W., Wang, F.Q., Fan, S.Y., et al., 2010b. Inactivation and augmentation of the primary 3-ketosteroid- $\Delta^{1}$ dehydrogenase in Mycobacterium neoaurum NwIB-01: biotransformation of soybean phytosterols to 4androstene-3,17-dione or 1,4-androstadiene-3,17-dione. Appl. Environ. Microbiol., 76(13):4578-4582. [doi:10. 1128/AEM.00448-10]

Wei, W., Fan, S.Y., Wang, F.Q., et al., 2014. Accumulation of androstadiene-dione by overexpression of heterologous 3-ketosteroid $\Delta^{1}$-dehydrogenase in Mycobacterium neoaurum NwIBib-01. World J. Microbiol. Biotechnol., 30(7):1947-1954. [doi:10.1007/s11274-014-1614-3]

Yao, K., Wang, F.Q., Zhang, H.C., et al., 2013. Identification and engineering of cholesterol oxidases involved in the initial step of sterols catabolism in Mycobacterium neoaurum. Metab. Eng., 15:75-87. [doi:10.1016/j.ymben. 2012.10.005]

Zhang, W.Q., Shao, M.L., Rao, Z.M., et al., 2013. Bioconversion of 4-androstene-3,17-dione to androst1,4-diene-3,17-dione by recombinant Bacillus subtilis expressing $k s d d$ gene encoding 3-ketosteroid- $\Delta^{1}$ dehydrogenase from Mycobacterium neoaurum JC-12. J. Steroid Biochem. Mol. Biol., 135:36-42. [doi:10.1016/j. jsbmb.2012.12.016]

Zhang, X., Zhang, R.Z., Yang, T.W., et al., 2013. Mutation breeding of acetoin high producing Bacillus subtilis blocked in 2,3-butanediol dehydrogenase. World $J$. Microbiol. Biotechnol., 29(10):1783-1789. [doi:10.1007/ s11274-013-1339-8]

Zhang, X., Zhang, X.F., Li, H.P., et al., 2014. Atmospheric and room temperature plasma (ARTP) as a new powerful mutagenesis tool. Appl. Microbiol. Biotechnol., 98(12): 5387-5396. [doi:10.1007/s00253-014-5755-y]

Zhang, X.Y., Peng, Y., Su, Z.R., et al., 2013. Optimization of biotransformation from phytosterol to androstenedione by a mutant Mycobacterium neoaurum ZJUVN-08. J. Zhejiang Univ.-Sci. B (Biomed. \& Biotechnol.), 14(2): 132-143. [doi:10.1631/jzus.B1200067]

Zheng, J.H., Wei, C.D., Zhao, L.N., et al., 2011. Combining blue native polyacrylamide gel electrophoresis with liquid chromatography tandem mass spectrometry as an effective strategy for analyzing potential membrane protein complexes of Mycobacterium bovis bacillus Calmette-Guérin. BMC Genomics, 12:40. [doi:10.1186/ 1471-2164-12-40] 


\section{中文概要}

题 目: 采用常压室温等离子体诱变技术获得一株高产雄 甾-4-烯-3,17-二酮的突变菌株 Mycobacterium neoaurum ZADF-4

目 的：获得一株高产雄甾-4-烯-3,17-二酮（AD）的 Mycobacterium neoaurum 突变株。

创新点：获得了一株 3-甾酮- $\Delta^{1}$-脱氢酶（KSDD）酶活缺 陷型的高产 $\mathrm{AD}$ 的诱变菌株 Mycobacterium neoaurum ZADF-4, 并采用菌落显色法笁选 KSDD 酶活缺陷型 M. neoaurum 突变株。

方 法: (1) 诱变方法: 采用常压室温等离子体 (ARTP) 诱变技术来处理出发菌株 M. neoaurum ZAD。 ARTP 诱变条件如下: 功率 $40 \mathrm{~W}$, 气流量 $12.5 \mathrm{~L} / \mathrm{min}$, 辐射距离 $1 \mathrm{~cm}$, 样品体积 $10 \mu \mathrm{l}$, 辐射 时间为 $60 、 90 、 120 、 150$ 和 $180 \mathrm{~s}$; 致死率统计 优化后, 最适辐射时间为 $150 \mathrm{~s}$, 致死率为 $90 \%$ 96\%。（2）篮选方法: 将 ARTP 诱变处理后的菌 株点种在硝酸纤维滤膜上, $30^{\circ} \mathrm{C}$ 培养 $2 \mathrm{~d}$, 然后 将长有菌落的滤膜小心取出并漂浮在 $4 \mathrm{mg} / \mathrm{ml}$ 二 氯静酚 (DCPIP) 溶液 $(0.1 \mathrm{mmol} / \mathrm{L}$ 磷酸缓冲液 $\mathrm{pH} 7.0 ） ， 30^{\circ} \mathrm{C}$ 培养 $1 \mathrm{~d}$ 直到全部菌落染成蓝色。 然后将该滤膜取出, 漂浮在 $250 \mathrm{mmol} / \mathrm{L} \mathrm{AD}$ 溶液 （2\%甲醇和 $50 \mathrm{mmol} / \mathrm{L}$ Tris pH 7.0 缓冲液），室 温放置 $15 \mathrm{~min}$ 左右, 观察菌落颜色变化。KSDD 在底物 $\mathrm{AD}$ 存在时会脱氢产生雄甾-1,4-二烯-
3,17-二酮（ADD）和 $\mathrm{H}^{+}, \mathrm{H}^{+}$可以使被 DCPIP 染 成蓝色的菌株褪色。因此, 酶活缺陷型的菌株会 仍保持蓝色, 而酶活高的菌株会褪色为黄色 （图 3)。（3）对获得的潜在的高产 $\mathrm{AD}$ 菌株进 行进一步的酶活检测以及产量验证, 以期获得最 优的突变株。

结 论: 获得了 4 株具有潜在的高产 $\mathrm{AD}$ 能力的菌株, 其 中, 最优的突变株 ZADF-4 的 KSDD 酶活相较于 出发菌株 ZAD 下降了 81.2\%（图 4）, 活性胶也 证明其 KSDD 酶活相较于出发菌株下降明显 (图 5)。薄层色谱法 (TLC) 和高效液相色谱法(HPLC) 实验证明突变株 ZADF-4 中, $\mathrm{AD}$ 的产量有了明 显的提高 (图 6 和图 7), 提高到了 $(6.28 \pm 0.11) \mathrm{g} / \mathrm{L}$, $\mathrm{AD} / \mathrm{ADD}$ 提高到 8:1, AD 的摩尔产率达到 $60.3 \%$ (表 1)。对出发菌株 ZAD 和突变株 ZADF-4 的 $k s d d$ 基因进行克隆和序列比对, 发现 ZADF-4 的 $k s d d$ 序列在 $5^{\prime}$ 端缺失 9 个核苷酸（atgttctac）, 导 致 3 个氨基酸 (MFY) 的缺失; 还发生了两个点 突变, 其中一个是无义突变 $($ g. $15 \mathrm{a}>6 \mathrm{t})$, 另一 个是有义突变 $(g .413 c>404 t)$, 并引起了相应位 置上的氨基酸变化（p.138S $>135 \mathrm{~L}$ ）。上述的基 因突变及其引起的氨基酸序列的变化可能是引 起 M. neoaurum ZADF-4 中 KSDD 酶活降低及 $\mathrm{AD}$ 产量提高的主要原因。

关键词: Mycobacterium neoaurum; 常压室温等离子体 (ARTP); 诱变育种; 雄甾-4-烯-3,17-二酮 (AD); 雄甾-1,4-二烯-3,17-二酮（ADD） 